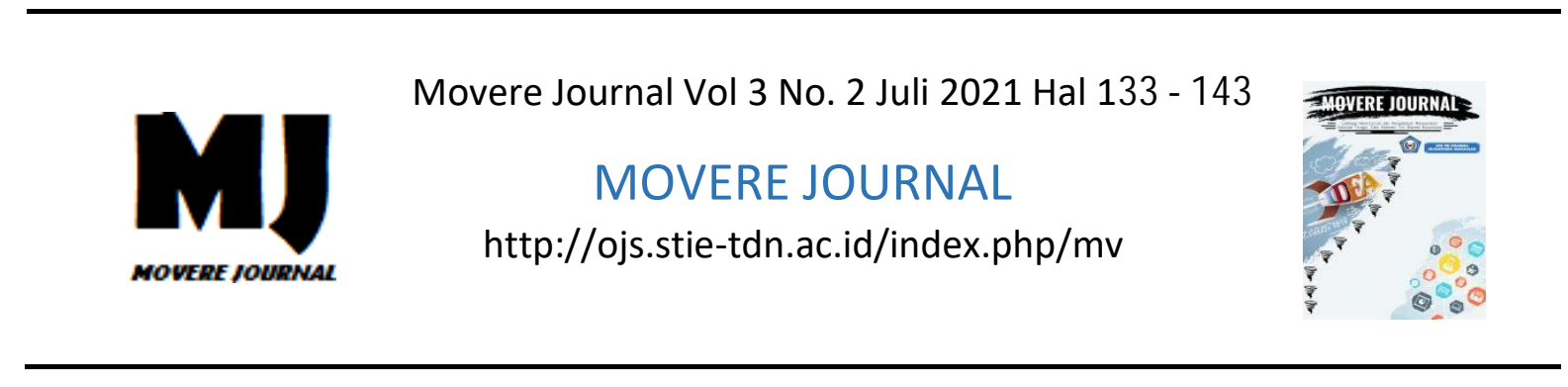

\title{
Pengaruh Kreativitas Periklanan Terhadap Keputusan Pembelian pada Konsumen Starbucks Coffee di Bandara Internasional Sultan Hasanuddin Makassar
}

\author{
Wendy Souisa \\ Politeknik Negeri Ambon \\ souisawendy@gmail.com
}

\begin{abstract}
Abstrak: Penelitian ini bertujuan untuk mengetahui pengaruh variabel iklan attention, interest, desire dan action terhadap pengambilan keputusan pembelian konsumen Starbucks Coffee di Bandara Internasional Sultan Hasanuddin Makassar. Dari penelitian ini dihasilkan bahwa ada pengaruh secara signifikan variabel variabel iklan attention, interest, desire dan action terhadap pengambilan keputusan pembelian konsumen Starbucks Coffee di Bandara Internasional Sultan Hasanuddin Makassar, dan diperoleh persamaan regresi yaitu : Y = 4,475 + 0,439 (X1) + 0,185 (X2) + 0,409 (X3) + 0,134 (X4) Dari persamaan di atas, terlihat bahwa variabel attention memiliki pengaruh yang lebih besar bila bandingkan dengan variabel lainnya. Pentingnya penilaian konsumen terhadap pengambilan keputusan pembelian prodak melaui iklan harus menjadi perhatian pihak perusahaan, olehnya itu perlu lebih meningkatkan kreatifitas dan kualitas pesan iklan dalam upaya memperoleh penilaian baik dari konsumen.
\end{abstract}

Kata Kunci : Keputusan Pembelian, Periklanan.

Abstract: This study aims to find out the effect of attention, interest, desire and action advertising variables to the decision making on consumer purchasing of Starbucks Coffee at Sultan Hasanuddin International Airport Makassar. This research found that there was a significant effect of attention, interest, desire and action advertising variables to the decision making on consumer purchasing decisions of Starbucks Coffee at Sultan Hasanuddin International Airport Makassar. And the regression equation was obtained: $Y=4,475+0,439(X 1)+0,185(X 2)+0,409(X 3)+0,134(X 4)$. From the equation above, it can be seen that the attention variable has a greater influence when compared to other variables. The importance of consumer assessment to the decision making in purchasing product through advertising must be a concern for the company. Therefore, it is necessary to further improve the creativity and quality of advertising messages in order to obtain good ratings from consumers.

Keywords: Purchase Decision, Advertising.

(C) 2021 STIE TDN. All rights reserved

Corresponding Author: Wendy

133 


\section{A. PENDAHULUAN}

Iklan merupakan salah satu media komunikasi pemasaran yang kerap digunakan dalam aktivitas ekonomi dalam upaya mengenalkan produk kepada konsumen. Situasi pasar yang kompetitif menjadikan tidak ada suatu bisnis yang mampu bertahan lama tanpa didukung oleh bauran komunikasi pemasaran semisal iklan yang efektif dan efisien. Iklan sebagai salah satu sarana pemasaran produk barang atau jasa harus mampu tampil menarik dan persuasif (Jefkins, 1997:15). Tentu ketika kita melihat semakin bertambahnya jumlah penduduk maka meniscayakan pula semakin besarnya kebutuhan masyarakat dalam kehidupan sehari-hari. Hal tersebut menjadi suatu konsekuensi bagi para produsen yang hadir dalam upaya menjawab pemenuhan kebutuhan masyarakat melihat hadirnya persaingan diantara berbagai perusahaan terkait. Salah satu jalan yang ditempuh oleh perusahaan adalah dengan kemampuan mengelola dan menyampaikan informasi kepada konsumen terkait produknya melalui aktivitas periklanan.

Pada sebuah iklan, baik yang dipublikasikan melalui media penyiaran maupun media cetak, pada dasarnya memiliki struktur. Struktur iklan pada kedua media tersebut pada dasarnya sama, hanya bentuknya berbeda karena perbedaan karateristik medianya. Yang paling mudah diamati adalah struktur iklan pada media cetak. Headline meliputi kepala tulisan letaknya tidak selalu pada bagian awal tulisan iklan. Yang paling penting headline iklan tersebut yang paling pertama dilihat orang. Subheadline, sebuah headline harus mengatakan sesuatu yang sangat penting kepada para calon pembeli. Biasanya berupa penjelasan tentang produk atau keunggulan barang atau jasa yang ditawarkan. Amplifikasi (perluasan) merupakan naskah atau teks iklan yang mengikuti headline. Sering juga disebut bodycopy/body text. Pada bagian ini konsepnya adalah penjelasan lebih rinci tentang produk atau barang/jasa yang ditawarkan. Untuk menghasilkan iklan yang baik selain memperhatikan struktur iklan diperlukan juga rumus iklan AIDA. Pertama yaitu, Attention berarti bahwa iklan harus mampu menarik perhatian khalayak sasaran. Untuk itu, iklan membutuhkan bantuan ukuran, penggunaan warna, tata letak atau suarasuara khusus. Kedua, Interest yang mana iklan berurusan dengan bagaimana konsumen berminat dan memiliki keinginan lebih jauh. Dalam hal ini konsumen harus dirangsang agar mau membaca, mendengar atau menonton pesan-pesan yang disampaikan. Perhatian harus segera ditingkatkan menjadi minat agar pembeli ingin mengetahui lebih rinci. Ketiga, Desire bermakna bahwa iklan harus mampu menggerakkan keinginan orang untuk memiliki atau menikmati produk tersebut. Iklan harus mampu menciptakan kebutuhan calon pembeli. Konsumen mulai goyah dan emosinya mulai tersentuh untuk membeli produk tersebut untuk menimbulkan rasa percaya pada diri pembeli dan memberikan pandangan positif pada konsumen tentang produk sebagai acuan dalam keputusan untuk membeli produk terhadap iklan. Kemudian, Action mengandung arti bahwa iklan harus memiliki "daya" membujuk calon pembeli agar sesegera mungkin melakukan suatu tindakan pembelian. Dalam hal ini dapat digunakan kata beli, ambil, hubungi, rasakan, gunakan dan 
lain-lain. Terlepas dari jenis usaha yang ditekuni oleh perusahaan, penting bagi perusahaan untuk memahami motif pembelian konsumen. Hal ini dikarenakan motif merupakan sesuatu yang menjadi dorongan bagi konsumen dalam berperilaku. Assauri (2007) dalam bukunya Manajemen Pemasaran mengatakan bahwa motif pembelian perlu dipelajari agar dapat diketahui alasan orang melakukan pembelian, sehingga dapat dilakukan kegiatan untuk menarik pembeli agar bersedia membeli produk yang ditawarkan. Setiadi (2010) juga mengatakan tujuan dari mempelajari motif pembelian konsumen adalah agar perusahaan dapat meningkatkan kepuasan konsumen, mempertahankan loyalitas, untuk efisiensi dan efektivitas, serta menciptakan suatu hubungan yang harmonis antara produsen atau penjual dan pembeli atau konsumen.

Seperti yang dilakukan oleh Starbucks Coffee Company, mereka menganggap semua bagian dari bisnis itu adalah penting. Manajemen Starbucks paham bahwa keunggulan kompetitif lahir bila semua pihak dalam perusahaan berpandangan bahwa tidak ada hal sepele dan bahwa pelanggan memperhatikan segalanya. (Joseph A. Michelli 2007). Starbucks Corporation (NASDAQ: SBUX) adalah sebuah jaringan kedai kopi dari Amerika Serikat yang bermarkas di Seattle, Washington. Starbucks adalah perusahaan kedai kopi terbesar di dunia, dengan 15.012 kedai di 44 negara. Starbucks Coffee merupakan perusahaan yang bergerak dibidang bisnis Coffee Retail, dimana perusahaan menyediakan hidangan kopi siap minum dengan ragam cara dan rasa yang digiling, dipanggang serta diseduh dari biji-biji kopi terbaik di seluruh dunia. Dengan pesatnya perkembangan industri ini, Starbucks Coffee perlu menerapkan strategi pemasaran yang tepat dalam upaya menghadapi serangan pesaingnya. Salah satu satrategi untuk menunjang kesuksesan pemsarannya adalah dengan periklanan.

Melihat banyaknya varian bentuk iklan yang dilakukan oleh Starbucks Coffee, pada penelitian ini berdasarkan ingin mengetahui apakah kegiatan iklan yang dilakukan Starbucks Coffee pada pengambilan keputusan konsumen membeli Starbucks Coffee, dan kriteria manakah yang memiliki pengaruh paling dominan untuk selanjutnya dapat menjadi bahan masukan bagi perumusan strategi iklan selanjutnya. Maka dari itu penulis mengambil judul "Pengaruh Kreativitas Periklanan Terhadap Keputusan Pembelian pada Konsumen Starbucks Coffee di Bandara Internasional Sultan Hasanuddin Makassar".

\section{B. TINJAUAN PUSTAKA}

\section{Iklan Sebagai Komunikasi Pemasaran}

Definisi pemasaran menurut Kotler (2000) pemasaran adalah proses sosial yang dengan proses itu individu dan kelompok mendapatkan apa yang mereka butuhkan dan inginkan dengan menciptakan, menawarkan dan secara bebas mempertukarkan barang dan jasa yang bernilai dengan pihak lain. Pendapat lain mengenai pemasaran dikemukakan oleh McDaniel dan Gates (2001) bahwa pemasaran adalah proses merencanakan dan melaksanakan konsep, memberi harga, melakukan promosi, mendistribusikan ide, barang dan jasa untuk menciptakan pertukaran yang memenuhi tujuan individu dan organisasi. Menurut Kotler dan Keller (2008) pemasaran terbagi atas 10 jenis 
entitas, yaitu : 1). Barang, 2).Jasa, 3).Pengayaan pengalaman, 4).Peristiwa, 5).Orang, 6).Tempat, 7).Properti, 8). Organisasi, 9). Informasi, 10). Gagasan. Komunikasi pemasaran melalui kegiatan promosi periklanan merupakan salah satu strategi dalam memperkenalkan atau menjelaskan produk yang di pasarkan. Strategi yang sering dipergunakan dalam membidik pasar sasaran adalah adanya pengelompokan pasar/segmen sebagai wilayah calon pembeli/pemakai. Pemilihan kelompok pasar yang spesifik akan lebih mudah mengkomunikasikan produk melalui media periklanan. Ciri atau karakter pada sekelompok segmen pasar merupakan data untuk memudahkan memasarkan produk.

Fungsi iklan dalam pemasaran adalah memperkuat dorongan kebutuhan dan keinginan konsumen terhadap suatu produk untuk mencapai pemenuhan kepuasannya. Agar iklan berhasil meransang tindakan pembeli, menurut Djayakusumah (1982) setidaknya harus memenuhi kriteria AIDA yaitu: Attention : mengandung daya tarik, Interest :mengandung perhatian dan minat, Desire : memunculkan keinginan untuk mencoba atau memiliki, Action : mengarah tindakan untuk membeli. Berdasarkan konsep AIDA, promosi periklanan memerlukan pengetahuan yang memadai tentang pola perilaku, kebutuhan, dan segmen pasar. Konsep tersebut mengharapkan konsumen dapat melakukan pembelian berkesinambungan. Segala daya upaya iklan dengan gaya bahasa persuasif berusaha membuat konsumen untuk mengkonsumsi, yang tidak memperdulikan status sosialnya. Cak Nun dalam Blank Magazine (2002) berpendapat, "iklan adalah anak jadah kebudayaan", yaitu bagaimana cara mengolah kelemahan produk menjadi kelebihan itulah fungsinya sebagai ujung tombak pemasaran.

\section{Keputusan Pembelian Sebagai Perilaku Konsumen}

Terdapat beberapa definisi perilaku konsumen yang dikemukakan oleh para pakar. Diantaranya menurut Engel (1995), perilaku konsumen ialah tindakan yang langsung terlibat untuk mendapatkan, mengkonsumsi dan menghabiskan produk atau jasa, termasuk proses keputusan yang medahului dan mengikuti tindakan tersebut. Lalu, Loudon dan Bitta (1988) lebih menekankan perilaku konsumen sebagai suatu proses pengambilan keputusan yang menyaratkan individu untuk mengevaluasi, memperoleh, menggunakan atau mengatur barang dan jasa. Kotler dan Amstrong (2006) mengartikan perilaku konsumen sebagai perilaku pembelian konsumen akhir baik individu maupun rumah tangga yang membeli produk untuk konsumsi personal. Model perilaku konsumen yang dikemukakan Kotler (2002) menerangkan bahwa keputusan konsumen dalam pembelian selain dipengaruhi oleh karakteristik konsumen, dapat dipengaruhi oleh rangsangan perusahaan yang mencakup produk, harga, tempat dan promosi. Variabel-variabel di atas saling mempengaruhi proses keputusan pembelian sehingga menghasilkan keputusan pembelian yang didasarkan pada pilihan produk, pilihan merek, 
pilihan penyalur, waktu pembelian dan jumlah pembelian.

\section{Hubungan Iklan Dan Pengambilan Keputusan Pembelian Konsumen}

Dalam memutuskan mengkonsumsi produk bisa dipengaruhi oleh informasi produk yang diiklankan, tampilan iklan yang menarik dan model yang ada di iklan. Hal ini menunjukkan bahwa iklan mempunyai peran yang sangat kuat dalam membujuk konsumen yang terjaring dalam lingkarannya terbius untuk mengikuti produk yang diinformasikan. Informasi media periklanan yang lancar dan mudah dipahami oleh masyarakat (konsumen) akan memberikan tanggapan yang positif bagi konsumen. Informasi yang jelas secara visual maupun verbal dan tidak menyinggung perasaan konsumen akan menguntungkan di pihak produsen. Harapan positif di hati masyarakat merupakan tujuan utama produsen dalam menawarkan produknya, sehingga bisa diterima di pasaran. Berbagai cara produsen dalam mempromosikan produknya melalui periklanan diharapkan mendapatkan citra positif konsumen.

Penilaian konsumen terhadap produk, yang dimaksud antara lain; Pertama, memperoleh penilaian baik dari konsumen. Penilaian dari konsumen sangat penting, karena dapat diketahui apakah yang diiklankan sudah diterima atau tertanam di hati konsumen. Bila iklan tidak diterima karena faktor penyimpangan budaya atau faktor lain yang dapat mengakibatkan ruginya produk yang diinformasikan melalui iklan. Sebagai contoh iklan produk Sanaflu yang slogannya "belum tahu dia" berhasil menjadi iklan favorit tahun 1998 karena begitu mudahnya mengingatkan pada produk yang diinformasikan, sehingga produk meningkat drastis. Sayangnya di wilayah Jawa Tengah produk ini kurang begitu laku dibandingkan dengan daerah lain, karena dianggap iklannya meremehkan budaya Jawa. Kedua, memupuk baik dan memberi pengertian tentang produk yang dibutuhkan konsumen. Ketiga, memperoleh etiket baik dari konsumen dalam membantu mempromosikan produk. Keempat, mengatasi prasangka buruk pada konsumen terhadap produk yang ditawarkan. Kelima, mendidik konsumen untuk menggunakan produk yang disajikan pada iklan. Informasi ini sering dilakukan melalui iklan produk obat-obatan. Keenam, memberikan penerangan dan pendidikan terhadap konsumen.

\section{Kerangka Konsep}

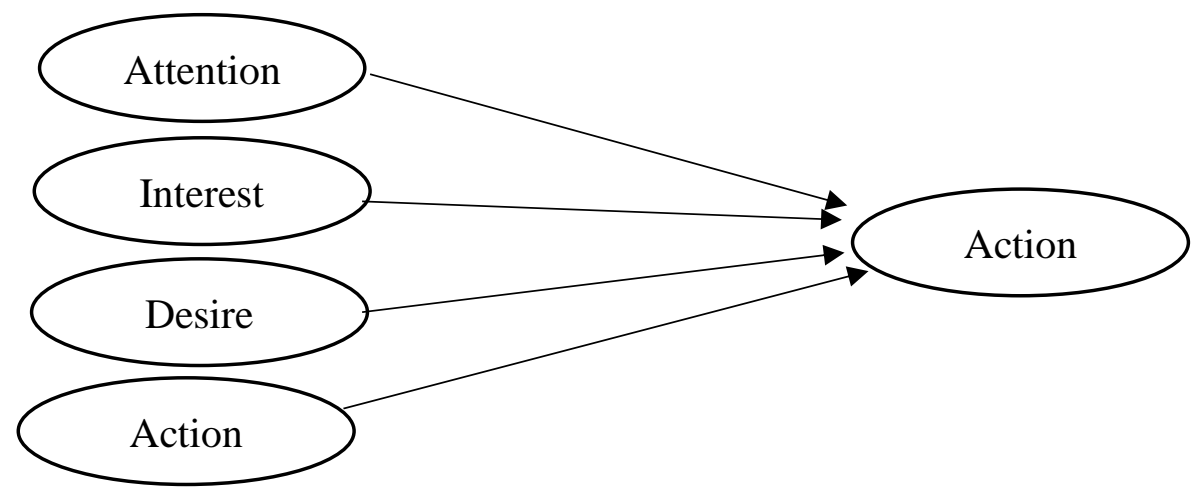

(C) 2021 STIE TDN. All rights reserved 
C. METODOLOGI PENELITIAN

\section{Populasi dan Sampel}

Pada penelitian ini, penulis menjadikan konsumen Starbucks Coffee Bandara Internasional Sultan Hasanuddin Makassar Makassar sebagai populasi dalam peneltian ini.. Prosedur yang kemudian digunakan untuk pengumpulan data adalah teknik probability sampling, yaitu teknik sampling yang memberikan peluang yang sama bagi setiap unsur (anggota) populasi untuk dipilih menjadi anggota sampel. Kemudian digunakan metode Simple Random Sampling. Dikarenakan jumlah populasinya tidak diketahui secara pasti maka untuk menentukan besarnya sampel yaitu dengan menggunakan rumus Unknown Populations: (Prasetya, 2011)

$$
n=\frac{Z^{2}}{4 \mu^{2}}
$$

Keterangan :

$n=$ ukuran sampel

$\mathrm{Z}=$ tingkat keyakinan sampel yang dibutuhkan dalam penelitian, pada $\alpha=5 \%$ (derajat keyakinan ditentukan 95\%) maka $\mathrm{Z}=1,96$

$\mu=$ margin of error, tingkat kesalahan yang dapat ditolerir (ditentukan 10\%)

\section{HASIL DAN PEMBAHASAN}

\section{Analisis Data}

Uji Reability dan Validitas
Dengan menggunakan rumus (1) diatas, maka diperoleh perhitungan sebagai berikut :

$n=\frac{Z^{2}}{4 \mu^{2}}$

$n=\frac{1,96^{2}}{4(0,1)^{2}}$

$n=96,4 \approx 100$ responden

Dari hasil perhitungan tersebut maka diketahui besar sampel yang diperlukan adalah 100 responden.

\section{Metode Analisis Data}

Pada penelitian ini terdapat satu variabel dependen dan empat variabel independen, maka alat analisis yang dipakai adalah analisis regresi berganda dengan menggunakan SPSS dengan rumus matematis sebagai berikut:

$Y=a+b_{1} X_{1}+b_{2} X_{2}+b_{3} X_{3}+b_{4} X_{4}$

Dimana :

$\mathrm{a}=$ konstanta

$\mathrm{b}=$ intensitas

$\mathrm{X}_{1}=$ Attention

$\mathrm{X}_{2}=$ Interest

$\mathrm{X}_{3}=$ Desire

$\mathrm{X}_{4}=$ Action

$\mathrm{Y}=$ Keputusan pembelian

Tabel 1. Reliability Statistics

\begin{tabular}{|c|c|c|}
\hline $\begin{array}{c}\text { Cronbach's } \\
\text { Alpha }\end{array}$ & $\begin{array}{c}\text { Cronbach's Alpha } \\
\text { Based on Standardized } \\
\text { Items }\end{array}$ & $\begin{array}{c}\mathrm{N} \text { of } \\
\text { Items }\end{array}$ \\
\hline, 820 &, 816 & 17 \\
\hline
\end{tabular}

(C) 2021 STIE TDN. All rights reserved 
Sumber: Data Primer, diolah 2021

Pengukuran yang digunakan dalam adalah reliabel. Berdasarkan hasil penelitian ini adalah dengan menggunakan alpha cronchbach (Reliabel), yaitu apabila alpha cronchbach lebih besar dari 0,6 atau perhitungan diperleh nilai Alpha Cronbach's sebesar 0,820, maka $60 \%$ maka item pertanyaan tersebut pertanyaan dalam penelitian di katakan reliabel.

Tabel 2. Item-Total Statistics

\begin{tabular}{|c|c|c|c|}
\hline Item & $\begin{array}{c}\text { Pearson } \\
\text { Correlation }\end{array}$ & $\mathrm{r}_{\text {Tabel }}$ & Keterangan \\
\hline $\mathrm{X}_{1.1}$ & 0,781 & 0,1996 & Valid \\
\hline $\mathrm{X}_{1.2}$ & 0,731 & 0,1996 & Valid \\
\hline $\mathrm{X}_{1.3}$ & 0,763 & 0,1996 & Valid \\
\hline $\mathrm{X}_{2.1}$ & 0,777 & 0,1996 & Valid \\
\hline $\mathrm{X}_{2} .2$ & 0,746 & 0,1996 & Valid \\
\hline $\mathrm{X}_{2} .3$ & 0,805 & 0,1996 & Valid \\
\hline $\mathrm{X}_{3 .} \cdot 1$ & 0,733 & 0,1996 & Valid \\
\hline $\mathrm{X}_{3 .} 2$ & 0,656 & 0,1996 & Valid \\
\hline $\mathrm{X}_{3.3}$ & 0,759 & 0,1996 & Valid \\
\hline $\mathrm{X}_{4.1}$ & 0,873 & 0,1996 & Valid \\
\hline $\mathrm{X}_{4.2}$ & 0,641 & 0,1996 & Valid \\
\hline $\mathrm{X}_{4.3}$ & 0,850 & 0,1996 & Valid \\
\hline $\mathrm{Y} 1$ & 0,311 & 0,1996 & Valid \\
\hline $\mathrm{Y} 2$ & 0,667 & 0,1996 & Valid \\
\hline $\mathrm{Y} 3$ & 0,667 & 0,1996 & Valid \\
\hline $\mathrm{Y} 4$ & 0,801 & 0,1996 & Valid \\
\hline $\mathrm{Y} 5$ & 0,767 & 0,1996 & Valid \\
\hline
\end{tabular}

Sumber: Data Primer, diolah 2017

Butir-butir pertanyaan dikatakan valid jika Apabila nilai Cronbach's Alpha if Item Deleted setiap pertanyaan $>0,30$ ) dan jika nilai dari masing-masing item pertanyaan memiliki nilai koefisien korelasi positif dan lebih besar dari pada $r$ table 


\section{Hasil Uji Regresi}

Tabel 3. Coefficients(a)

\begin{tabular}{|c|c|c|c|c|c|c|}
\hline \multirow{2}{*}{\multicolumn{2}{|c|}{ Model }} & \multicolumn{2}{|c|}{ Unstandardized Coefficients } & \multirow{2}{*}{$\begin{array}{c}\text { Standardized } \\
\text { Coefficients } \\
\text { Beta } \\
\end{array}$} & \multirow[t]{2}{*}{$\mathrm{t}$} & \multirow[t]{2}{*}{ Sig. } \\
\hline & & $\mathrm{B}$ & Std. Error & & & \\
\hline \multirow[t]{8}{*}{1} & (Constant) & 4.475 & 1.905 & & 2.354 & .021 \\
\hline & Attention & .439 & .054 & .359 & 4.617 & .000 \\
\hline & Interest & .185 & .063 & .116 & 2.622 & .001 \\
\hline & Desire & .409 & .061 & .409 & 4.449 & .000 \\
\hline & Interest & .134 & .075 & .115 & 2.331 & .001 \\
\hline & $\mathrm{F}$ & & & & 24,581 & $.000^{\mathrm{a}}$ \\
\hline & $\mathrm{R}$ & & & & ,713 & \\
\hline & R Square & & & & ,509 & \\
\hline
\end{tabular}

a. Dependent Variable: Keputusan pembelian

Sumber: Data Primer, diolah 2017

Hasil pengolahan dan komputerisasi menunjukkan persamaan regresi berganda sebagai berikut :

$\mathrm{Y}=\mathbf{4 , 4 7 5}+\mathbf{0 , 4 3 9}(\mathrm{X} 1)+\mathbf{0 , 1 8 5}(\mathrm{X} 2)$ $+0,409(X 3)+0,134(X 4)$

Persamaan regresi di atas dapat dijelaskan sebagai berikut :

1. $\mathrm{a}=4,475$ artinya jika $\mathrm{X}_{1}$ (attention) $=\mathrm{X}_{2}$ (interest) $=\mathrm{X}_{3}$ $($ desire $)=\mathrm{X}_{4}($ action $)=0$, maka pengambilan keputusan pembelian konsumen sebesar 4,475.

2. $b_{1}=0,439$ menunjukkan bahwa jika variabel attention $\left(\mathrm{X}_{1}\right)$ meningkat sebesar 1\%, maka pengambilan keputusan pembelian konsumen Starbucks Coffee akan meningkat sebesar 0,439 dengan asumsi $\mathrm{X}_{2}, \mathrm{X}_{3}$, dan $\mathrm{X}_{4}$ konstan.

3. $b_{2}=0,185$ menunjukkan bahwa jika variabel interest $\left(\mathrm{X}_{2}\right)$ meningkat sebesar 1\%, maka pengambilan keputusan pembelian konsumen Starbucks Coffee akan meningkat sebesar 0,185 dengan asumsi $\mathrm{X}_{1}, \mathrm{X}_{3}$, dan $\mathrm{X}_{4}$ konstan.

4. $\mathrm{b}_{3}=0,409$ menunjukkan bahwa jika variabel desire $\left(\mathrm{X}_{3}\right)$ meningkat sebesar 1\%, maka pengambilan keputusan pembelian konsumen Starbucks Coffee akan meningkat sebesar 0,409 dengan asumsi $\mathrm{X}_{1}, \mathrm{X}_{2}$, dan $\mathrm{X}_{4}$ konstan.

5. $\mathrm{b}_{4}=0,134$ menunjukkan bahwa jika variabel action $\left(\mathrm{X}_{4}\right)$ meningkat sebesar 1\%, maka pengambilan keputusan pembelian konsumen Starbucks Coffee akan meningkat sebesar 0,134 dengan asumsi $\mathrm{X}_{1}, \mathrm{X}_{2}$, dan $\mathrm{X}_{3}$ konstan.

Selanjutnya melihat uji $\mathrm{F}$ dengan syarat F-hitung $>\quad F_{\text {-tabel }}$ dan hasil penelitian diperoleh 24,581 > 2,47, maka dapat disimpulkan bahwa $\mathrm{H}_{1}$ diterima, artinya ada pengaruh secara signifikan variabel iklan attention, interest, desire dan action secara bersama-sama terhadap pengambilan 
keputusan pembelian konsumen Starbucks Coffee di Bandara Internasional Sultan Hasanuddin Makassar

Tabel 3 menunjukkan bahwa angka koefisien determinasi atau $\mathrm{R}$ square sebesar 0,509 atau menunjukkan angka $50,9 \%$ atau bisa dibulatkan menjadi $51 \%$, hal ini berarti variabel iklan attention, interest, desire dan action berpengaruh terhadap pengambilan keputusan pembelian konsumen Starbucks Coffee sebesar $51 \%$ dan sisanya dipengaruhi oleh variabel lainnya yang tidak diteliti dalam penelitian ini.

\section{Pembahasan}

1. Variabel Attention

Berdasarkan hasil pengujian yang didasarkan pada hipotesis diketahui bahwa untuk variabel attention berpengaruh signifikan dalam tingkatan yang paling dominan terhadap pengambilan keputusan pembelian Starbucks Coffee di Bandara Internasional Sultan Hasanuddin Makassar. Variabel attention merupakan salah satu aspek yang menjadi tahap awal dari suatu iklan yang disimak oleh tiap calon konsumen. Terlebih lagi perusahaan menjadikan variabel ini sebagai pondasi dalam upaya memperkenalkan produknya dan membangun citra perusahaan lewat berbagai media. Tentu Pelanggang merasakan langsung bagaimana kehadiran produk yang diperkenalkan.

Dimana dari item pertanyaan kuisioner, jawaban yang di berikan Pelanggang sebagai responden mengindikasikan bahwasanya berdasarkan definisi operasional variabel penilitian terkait indikator informasi, proses mengingat produk dan visualisasi yang menarik perhatian mampu menarik perhatian calon konsumen dalam hal ini Pelanggang yang kemudian akan dapat dimanfaatkan lebih lanjut bagi pihak Perusahaan agar para calon konsumen ini menjadi konsumen yang kemudian membeli produk mereka.

\section{Variabel Interest}

Berdasarkan hasil pengujian yang diperoleh dari penelitian yang dilakukan diketahui bahwa untuk variabel interest berpengaruh signifikan terhadap keputusan pembelian Starbucks Coffee di Bandara Internasional Sultan Hasanuddin Makassar. Variabel interest hadir dalam tahapan selanjutnya yang menggambarkan bagaimana calon konsumen menerima pesan yang disampaikan lewat iklan produk Starbucks Coffee di Bandara Internasional Sultan Hasanuddin Makassar untuk memenuhi dan membangun apa yang dibutuhkan oleh konsumen dari produk yang ditawarkan.

Berdasarkan definisi operasional variabel penelitian yang dikaitkan pada item pertanyaan kuisioner, jawaban yang di berikan Pelanggang sebagai responden mengindikasikan pula bahwasanya indikator kreativitas dan pesan terhadap karakteristik produk melalui iklan, calon konsumen dalam hal ini Pelanggang mampu memperoleh kesan dan manfaat melalui pesan iklan produk dari pihak Perusahaan selaku perusahaan pemasar agar calon 
konsumen ini memiliki referensi yang cukup jelas untuk membeli produk yang ditawarkan.

3. Variabel Desire

Berdasarkan hasil pengujian diketahui bahwa untuk variabel desire berpengaruh signifikan terhadap keputusan pembelian Starbucks Coffee di Bandara Internasional Sultan Hasanuddin Makassar. Pada variabel ini konsumen berada pada tahapan untuk mencerna dan memahami makna pesan iklan. Definisi operasional variabel penelitian meliputi indikator perolehan informasi yang berkaitan dengan iklan, minat konsumen akan iklan, kepercayaan konsumen akan produk. Hal tersebut mendorong calon konsumen untuk mempertimbangkan bagaimana produk dapat memberikan pengaruh atau dapat memenuhi kebutuhan konsumen. Terlebih lagi ketika dihadapkan dengan hadirnya produk serupa dari perusahaan lain. Kemudian bagaimana variabel desire ini mampu mendorong kebutuhan konsumen untuk tertarik lebih jauh untuk menggunakan produk yang telah ditawarkan.

\section{Variabel Action}

Berdasarkan hasil pengujian dalam penelitian diketahui bahwa untuk variabel action juga berpengaruh signifikan terhadap keputusan pembelian Starbucks Coffee di Bandara Internasional Sultan Hasanuddin Makassar. Tumbuhnya kesadaran dan keyakinan konsumen terhadap produk baik lewat pengalaman penggunaan sebelumnya hingga terkhusus melalui iklan akan mendorong konsumen untuk mengambil langkah dalam menggunakan Starbucks Coffee di Bandara Internasional Sultan Hasanuddin Makassar dengan membeli baik sebatas untuk mencoba hingga untuk menggunakannya secara berkelanjutan. Dimana berdasarkan definisi operasional variabel penelitian yang meliputi indikator untuk membujuk konsumen melakukan tindakan pembelian dan mampu membuat khayalak melakukan tindakan sesuai yang diinginkan, yang kemudian mengarah pada tindakan pembelian nyata, konsumen dapat menilai apakah produk yang digunakan sesuai sebagaimana dengan apa yang telah diperkenalkan dan disampaikan melalui iklan sebelumnya. Hal tersebut yang menjadi suatu acuan apakah konsumen menikmati dan puas atau tidak dalam menggunakan produk.

\section{E. KESIMPULAN}

Berdasarkan hasil penelitian maka penulis menyimpulkan pentingnya penilaian konsumen terhadap pengambilan keputusan pembelian prodak melaui iklan. Pihak perusahaan perlu lebih meningkatkan kreatifitas dan kualitas pesan iklan dalam upaya memperoleh penilaian baik dari konsumen serta memupuk dan memberi pengertian tentang produk yang dibutuhkan oleh konsumen. Tentu menjadi suatu nilai lebih ketika kepercayaan dan kepuasan konsumen terhadap produk turut membangun etikad baik dari konsumen dalam membantu mempromosikan produk dan mengatasi prasangka buruk pada konsumen terhadap produk yang 
ditawarkan. Maka, dalam hal yang lebih luas dalam kehidupan Pelanggang perusahaan turut bertanggung jawab dalam mendidik konsumen tidak hanya untuk menggunakan produk yang disajikan pada iklan tetapi memberikan pencerahan dan pendidikan terhadap konsumen atau Pelanggang secara umum.

\section{DAFTAR PUSTAKA}

Assauri, Sofjan, 2007, Manajemen Pemasaran, Rajawali Pers, Jakarta.

Carl McDaniel dan Roger Gate, 2001, Riset Pemasaran Kontemporer, Jakarta: Salemba Empat

Djayakusuma, Tams. 1982. Periklanan. Bandung: Armico

Engel, J.F., Blackwell,R.D., \& Miniard, P.W. (1995). Consumer Behavior. 8th Ed. Forth Worth, Texas: The Dryden Press.

Jefkins, Frank, 1997, Periklanan, Jakarta: Erlangga.
Joseph. A. Micheli 2007, The starbucks Coffee : 5 Prinsip untuk mengubah hal biasa Menjadi Luar Biasa, Esensi.

Kotler, Philip, 2000, Marketing Management, New Jersey: The Millennium Edition, Prentice Hall International Edition.

Kotler, Philip dan Kevin Lane Keller, 2008, Manajemen Pemasaran, Jilid Satu, Edisi Keduabelas, Cetakan Ketiga, Penerbit Indeks.

Kotler, Philip dan Gary Amstrong, 2006, Prinsip-Prinsip Pemasaran, Jilid 1, Edisi 12, Terjemahan: Bob Sabran, M.M, Jakarta: Erlangga

Prasetya. 2011. Metode Penelitian Kuantitatif. Jakarta: Rajawali Pers.

Setiadi, Nugroho J. (2010). Perilaku Konsumen. Cetakan 4. Edisi Revisi. Jakarta: Kencana 